\title{
CIÊNCIA DO SOLO NAS ESCOLAS DE ENSINO FUNDAMENTAL E MÉDiO
}

\author{
Eduardo Canepelle ${ }^{1}$, Jessica Taís Kerkhoff ${ }^{1}$, Thaniel Carlson Writzl ${ }^{1}$, Jackson Eduardo Schmitt Stein ${ }^{1}$, \\ Danni Maisa da Silva², Marciel Redin ${ }^{2}$
}

\begin{abstract}
RESUMO - O solo é conhecido como um dos principais recursos necessários para vida na Terra, pois realiza vários processos imprescindíveis para a sustentabilidade dos ecossistemas, como o armazenamento de água e carbono. O trabalho teve como objetivo difundir a Ciência do Solo nas escolas de ensino fundamental e médio do meio urbano e rural, do município de Três Passos/RS, bem como ampliar o interesse dos discentes na conservação e valorização do solo. Foram realizadas ações de extensão em cinco escolas, nas quais foram realizadas atividades nos mais diversos formatos atrativos (aulas/palestras e atividades práticas). Entre as atividades práticas sobre o uso de práticas que visam a conservação do solo estava o uso da cobertura verde, adubação orgânica, cultivo em nível, uso de terraços, entre outras. A grande maioria dos estudantes considerou possuir interesse em estudar o tema solo como uma disciplina na escola, sendo assim a partir das atividades realizadas nas escolas criou-se novo paradigma onde os estudantes passaram ter nova concepção sobre o solo. Entretanto, os estudantes possuem conhecimento restrito sobre Pedologia, sendo assim, portanto, a necessidade de serem desenvolvidas, com os discentes, novas ações que estejam voltadas à Ciência do Solo.
\end{abstract}

Palavras chave: conhecimento de solo, conservação do solo, educação em solos, sustentabilidade ambiental.

\section{SOIL SCIENCE IN PRIMARY AND SECONDARY SCHOOLS}

\begin{abstract}
Soil is known as one of the main resources needed for life on Earth because it performs several processes essential for the sustainability of ecosystems, such as water and carbon storage. The objective of this work was to disseminate Soil Science in primary and secondary schools in the urban and rural environment of the municipality of Três Passos/RS, as well as to increase students interest in soil conservation and valorization. Extension actions were carried out in five schools, where activities were carried out in the most diverse attractive formats (lectures/lectures and practical activities). Among the practical activities on the use of practices aimed at soil conservation was the use of green cover, organic fertilization, level cultivation, use of terraces, among others. The great majority of students considered having an interest in studying the subject as a subject in the school, so from the activities carried out in the schools, a new paradigm was created where the students had a new conception about the soil. However, the students have limited knowledge about Pedology, and therefore, the need to develop, with the students, new actions that are focused on Soil Science.
\end{abstract}

Keywords: Soil education, soil conservation, soil knowledge, environmental sustainability.

\footnotetext{
${ }^{1}$ Acadêmicos do Curso de Bacharelado em Agronomia. Universidade Estadual do Rio Grande do Sul - UERGS. Unidade em Três Passos, Rua Cipriano Barata, 211 - Bairro Érico Veríssimo, Três Passos. CEP: 98600-000. Contato: (55) $3522-2895$. E-mails: eduardocanepelle@gmail.com; jessica_kerkhoff@hotmail.com; thaniel.cw@hotmail.com,jackson.s.stein@hotmail.com

${ }^{2}$ Docentes da Universidade Estadual do Rio Grande do Sul - UERGS. Unidade em Três Passos, Rua Cipriano Barata, 211 - Bairro Érico Veríssimo - Três Passos. CEP: 98600-000. Contato: (55) 3522-2895. E-mails: danni-silva@uergs.edu.br; marcielredin@gmail.com.br
} 


\section{INTRODUÇÃO}

A utilização do solo pelos humanos para produção de alimentos começou a aproximadamente 11.000 anos atrás, estendendo-se até os dias atuais (White, 2010). A partir da década de 60, a agricultura no contexto mundial passou por nova fase, a revolução verde, onde sistemas de produção passaram utilizar o modelo de agricultura tecnológica o qual trouxe inúmeras mudanças na forma de realizar agricultura, como utilização intensiva do solo. De acordo com Lima et al. (2016), a adoção destas novas tecnologias aumentou-se a exploração da natureza com a retirada de recursos, visando o aumento na produtividade, acarretando grande degradação ambiental, em especial, a degradação do solo devido a seu uso excessivo. White (2010) ressalta o aumento da conversão das terras em cultivos, muitas das quais não são ideais para produção agrícola por causa das limitações do clima, do solo e da topografia. Sendo assim, o manejo inadequado do solo tem provocados vários problemas ambientais como: erosão, poluição, deslizamentos, assoreamento de cursos d'água, desertificação, perda da fertilidade natural, salinização, contaminação, compactação, entre outros (Perusi \& Sena 2012, Boas et al. 2012). Assim, a degradação dos solos constitui um prejuízo socioeconômico para as gerações atuais e representa um enorme risco para as gerações futuras (Lepsch, 2010). Segundo White (2010), as perdas de solos agrícolas em nível mundial se dão a uma taxa de 6 a 7 milhões de hectares por ano.

Apesar do solo realizar vários processos imprescindíveis para planeta terra, a maior parte da sociedade o considera apenas para descarte de resíduos ou como meio para criação e multiplicação de patógenos, pois segundo Lima et al. (2007), o espaço dedicado ao solo, no ensino fundamental e médio, é frequentemente nulo ou relegado a um plano menor, tanto na área urbana como rural. Este conteúdo nos materiais didáticos, muitas vezes, está em desacordo com os Parâmetros Curriculares Nacionais (PCNs) e, frequentemente encontra-se desatualizado, incorreto ou fora da realidade dos solos brasileiros. Além disso, ainda segundo Lima et al. (2007), muitas vezes este assunto é ministrado de forma estanque, sem relacionar-se com a utilidade prática ou cotidiana desta informação, causando desinteresse tanto ao discente quanto ao docente.

Entretanto, atualmente, existem alguns esforços para mudar esta realidade, a fim de evidenciar a importância do solo para a vida no planeta Terra, bem como a promoção de uma agricultura ecologicamente correta e valorização do ambiente. Nesse sentido, a Organização das Nações Unidas (ONU) decretou em 2015 como o ano internacional dos solos com o tema "Healthy Soils for a Healthy Life" para mostrar a importância que o mesmo tem para vida no planeta (Redin et al., 2016). A percepção das pessoas em relação ao solo, pode ser realizada de forma individual ou coletiva, diante de uma concepção que valorize os princípios da sustentabilidade, na qual valores e atitudes de desvalorização do solo possam ser revistos e reconstruídos. Essa mudança no paradigma da sociedade pode nascer de um processo educativo, pois a educação pode contribuir efetivamente para esse processo, uma vez que ela oferece instrumentos para elaborar e reelaborar valores, atitudes e condutas (Muggler et al. 2006). Os jovens são o futuro da sociedade, sendo assim, o entendimento e condutas que sociedade terá no futuro depende das ações realizadas no presente.

Assim, face que são raras ações que demostram a importância no solo na região noroeste do Rio Grande do Sul, o presente trabalho teve como objetivo difundir a Ciência do Solo nas escolas de ensino fundamental e médio do meio urbano e rural do município de Três Passos, RS, bem como ampliar o interesse dos discentes na conservação e valorização do solo.

\section{MATERIAL E MÉTODOS}

As ações de extensão foram realizadas no ano letivo de 2017, em cinco escolas, sendo quatro escolas de ensino fundamental, turmas dos $8^{\circ}$ e $9^{\circ}$ anos, pertencentes a rede municipal as quais são localizadas no meio rural e uma no meio urbano com estudantes do $3^{\circ}$ ano do ensino médio, provenientes do meio rural do município de Três Passos, RS. As ações foram realizadas em um dia para cada escola. Para desenvolver as ações propostas, foi estabelecido incialmente contato com secretaria municipal de educação, a fim de levar conhecimento da mesma os objetivos e metodologia que seria empregada para desenvolvimentos das ações nas escolas. Após análise da proposta do projeto optouse em realizar as atividades, preferencialmente em escolas do meio rural, uma vez que secretaria de educação do munícipio já possui projeto similar intitulado "Projeto Semeando" o qual desenvolve semanalmente atividades com os estudantes, porém com objetivo de ensinar técnicas agrícolas. As atividades desenvolvidas 
envolveram os estudantes e professores, mostrando que o solo desempenha papéis fundamentais para a vida no planeta Terra.

No primeiro momento foram realizadas as apresentações pessoais dos integrantes que desenvolveriam as ações, após foi apresentado o projeto, quais que eram os objetivos a serem alcançados e metodologia que seria utilizada, além de ouvir a opinião dos estudantes em relação qual era a expectativa deles sobre o projeto. Após isto foi aplicado um questionário aos estudantes com questões objetivas, a fim de fazer um diagnóstico sobre o conhecimento inicial dos mesmos sobre o solo, além do levantamento do perfil dos estudantes. O questionário aplicado nesta fase tinha finalidade principal de verificar o conhecimento sobre a Ciência do Solo antes de qualquer interferência por parte deste trabalho. O questionário continha dez questões sendo elas: idade? sexo? o que é solo? qual a origem do solo? você tem conhecimento sobre os organismos vivos que habitam o solo? o assunto solo é abordado nas disciplinas do colégio? já participou de algum evento ou palestra sobre solos? quais são as causas da degradação do solo? você conhece os benefícios da preservação do solo e adubação verde e se possui interesse em estudar os solos na escola como uma disciplina? Logo após, foram desenvolvidas aulas expositivas e palestras, as quais abordaram os seguintes tópicos: os processos e fatores de formação do solo; o solo e suas funções ambientais e mantenedoras da vida; conservação do solo; poluição do solo; degradação do solo; composição do solo, a água e ar no solo; biologia e microbiologia do solo; adubação verde, plantas de cobertura de solo e recuperação de áreas degradadas.

Posteriormente, foram realizadas atividades práticas com o intuito dos estudantes visualizarem de forma prática os assuntos anteriormente abordados na teoria, e assim, melhorar a aprendizagem dos escolares, uma vez que maioria das escolas são escassas as atividades práticas, em complementação os assuntos teóricos abordados na sala de aula. Para a realização das atividades práticas utilizou-se recursos disponíveis na escola, sendo que apenas alguns materiais e equipamentos de laboratório foram levados da universidade até as escolas. As atividades práticas realizadas foram em relação as plantas de cobertura de solo, momento onde foram apresentadas as sementes, fotos e alguns exemplares das mesmas, onde os estudantes puderam visualizar e manipular os materiais, bem como também puderam observar o sistema radicular das plantas e, finalmente os benefícios que as mesmas proporcionam ao solo. Outra atividade prática foi relacionada a perda de solo através de uma simulação de três formas de preparo de solo, solo coberto palha, solo descoberto e solo coberto com grama. Estas simulações tinham intuito de mostrar na forma prática a importância da cobertura de solo em reduzir as perdas de solo, evitando desta forma a degradação do mesmo. Ainda, foram realizadas atividades práticas, sobre o uso de práticas de manejo adequadas à conservação do solo como cobertura verde, adubação orgânica, cultivo em nível, uso de terraços, entre outras. Por fim, foram realizadas ações práticas que demostrassem a presença dos microrganismos existentes no solo, por meio da coleta de solo em área próxima a delimitação das escolas, uma amostra foi preparada e colocada em placas de petri com meio de cultura para avaliar a presença e desenvolvimentos de microrganismos do solo.

Após as ações teóricas e práticas foram aplicados questionários aos estudantes, afim avaliar se as ações desenvolvidas contribuíram para o conhecimento sobre a Ciência do Solo, além avaliar na percepção dos estudantes se o projeto conseguiu atingir os objetivos esperados pelos estudantes. Este questionário continha seis questões sendo cinco objetivas e uma descritiva, sendo elas: o minicurso atendeu os seus objetivos? você conseguiu notar a importância do solo para a humanidade? você conseguiu notar a importância dos organismos do solo, da preservação do solo e adubação verde? você considera importante trabalhar o tema solos nas disciplinas da escola? você considera as atividades práticas importantes para o aprendizado em solos, e quais técnicas podem ser utilizadas para melhorar a preservação do solo? As respostas dos questionários foram analisadas e confrontadas a fim de elaborar figuras comparativas e explicativas.

\section{RESULTADOS E DISCUSSÃO}

Dos 64 estudantes que participaram do projeto, $56 \%$ foram do sexo masculino e $44 \%$ do sexo feminino (Figura 1), sendo assim, observou-se maior participação dos estudantes que residem no meio rural são do sexo masculino. De acordo com Maurina (2011), a maior parte dos jovens do campo são do sexo masculino pela alta taxa de êxodo rural das mulheres, principalmente daqueles da agricultura familiar, mesmo de idade escolar, 


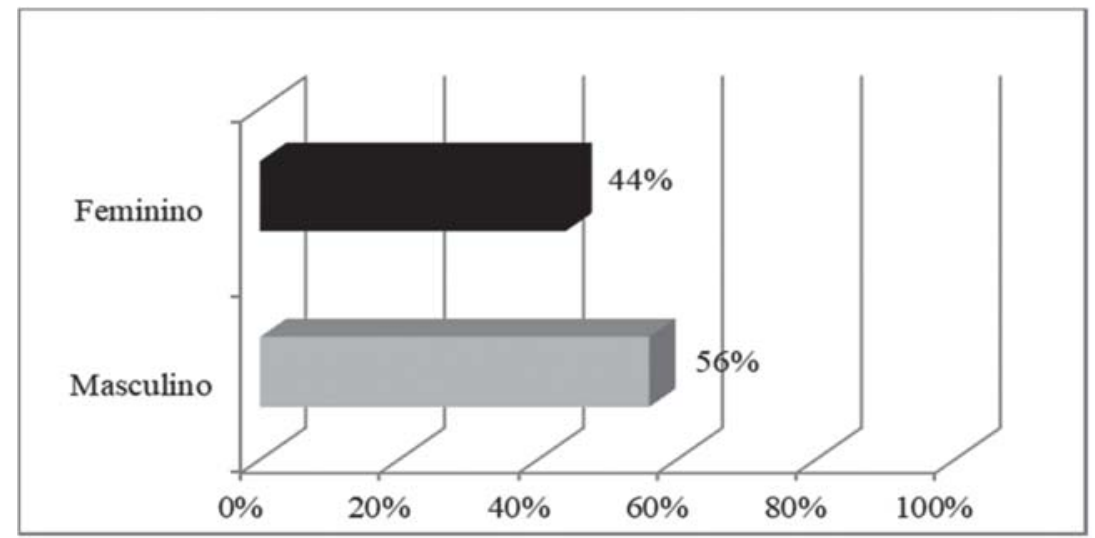

Figura 1 - Estudantes que participaram das ações de extensão sobre Ciência do Solo.

principalmente os jovens. Diante disso, as crianças e a juventude na área rural estão recebendo notória atenção, tendo em vista a sua importância para a sustentabilidade no meio rural. Ainda, de acordo com Maurina (2011), a busca por oportunidades de estudo e trabalho pelos jovens nas cidades causou mudanças na estrutura social das comunidades rurais, assim como impactos sobre vários aspectos culturais, sociais e econômicos.

Antes de ser realizada qualquer interferência por parte das ações teóricas e práticas do projeto, a aplicação do questionário relacionado a vários temas relevantes da Ciência do Solo mostraram que grande maioria dos estudantes não possuíam conhecimento sobre o conceito de solo $(80 \%)$, respondendo incorretamente quando questionados sobre o conceito de solo, e apenas $16 \%$ responderam corretamente (Figura 2). Os resultados obtidos mostram de forma evidente que estudantes não possuem conhecimento sobre solo, pois apenas $16 \%$ conseguiram observar que solo é constituído pelas partes sólida, líquida e gasosa.

Do total dos estudantes, 56\% nunca tinham participado de um evento ou palestra sobre solos (Figura 3), embora a Região Noroeste é extremamente agrícola, onde solo apresenta uma enorme importância para desenvolvimento da agricultura, são raras ações de difusão desenvolvidas sobre a Ciência do Solo. Esta constatação fica evidente quando apenas 7\% dos estudantes tem conhecimento sobre qual é origem do solo (Figura 4). Em contrapartida $81 \%$ dos estudantes responderam ter conhecimento sobre os organismos que habitam o solo e $89 \%$ afirmaram que assunto solo é abordado, embora de forma superficial, na disciplina de biologia (Figura 3 ).

Em relação ao conhecimento sobre os organismos que existem no solo, Lima et al. (2016), em trabalho na mesma temática encontraram resultados similares, onde $81,3 \%$ das pessoas estudas responderam possuir conhecimento que existe vida no solo e que está diretamente relacionada com sua produtividade de alimentos, forragens e fibras. De acordo com Dionísio et al. (2014), a quantidade e diversidade de microrganismos e animais invertebrados que habitam o solo, não seria exagero considerá-lo, do ponto de vista biológico, como sendo "um organismo vivo". Também não seria exagero considerar que, do ponto de vista agrícola e ambiental, "só existe solo se nele estiver vida" e que, sendo assim, "não existe solo estéril (sem vida)". No entanto, segundo Dionísio et al. (2014), a maioria das pessoas pensam que todos ou pelo menos a maior parte dos microrganismos são prejudiciais e, por essa razão, seria altamente desejável que não existissem ou que fossem todos eliminados do solo. Ainda, segundo os autores essa concepção é definitivamente falsa e errada e, mesmo que fosse possível a completa eliminação dos microrganismos, seria eliminada também a possibilidade de vida no planeta, uma vez que nossa própria sobrevivência depende da existência deles. No entanto, estes organismos que são de fundamental importância para solo podem ter sua diversidade e quantidade muito diminuída ou até exterminada por ações antrópicas. Segundo Dionísio et al. (2014), o uso de agrotóxicos, o cultivo intensivo do solo, a monocultura prolongada e as queimadas, 


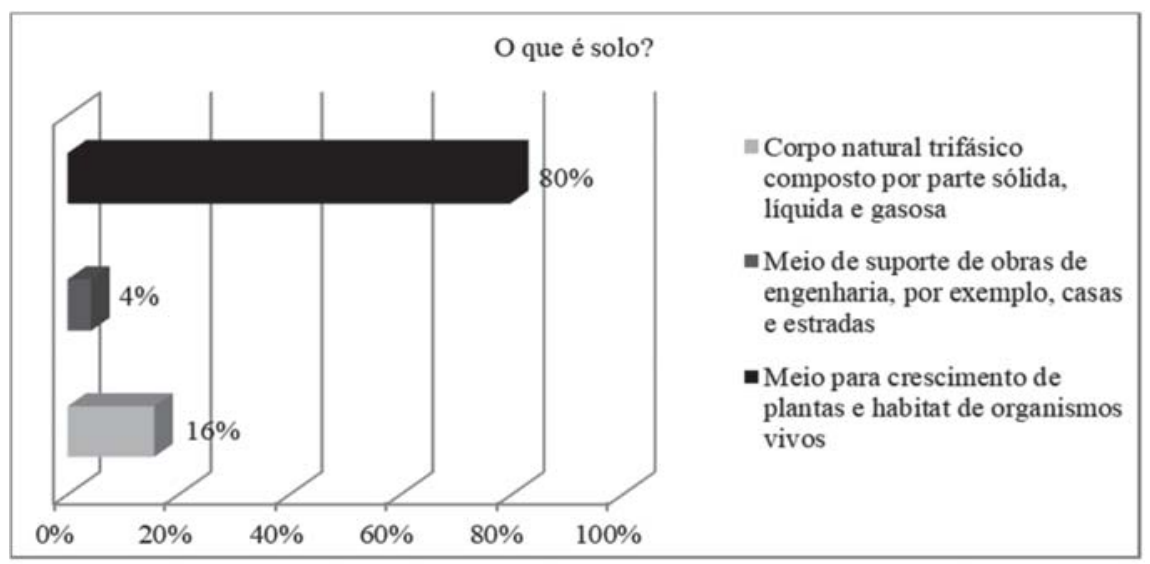

Figura 2 - Conhecimento dos estudantes sobre o conceito de solo.

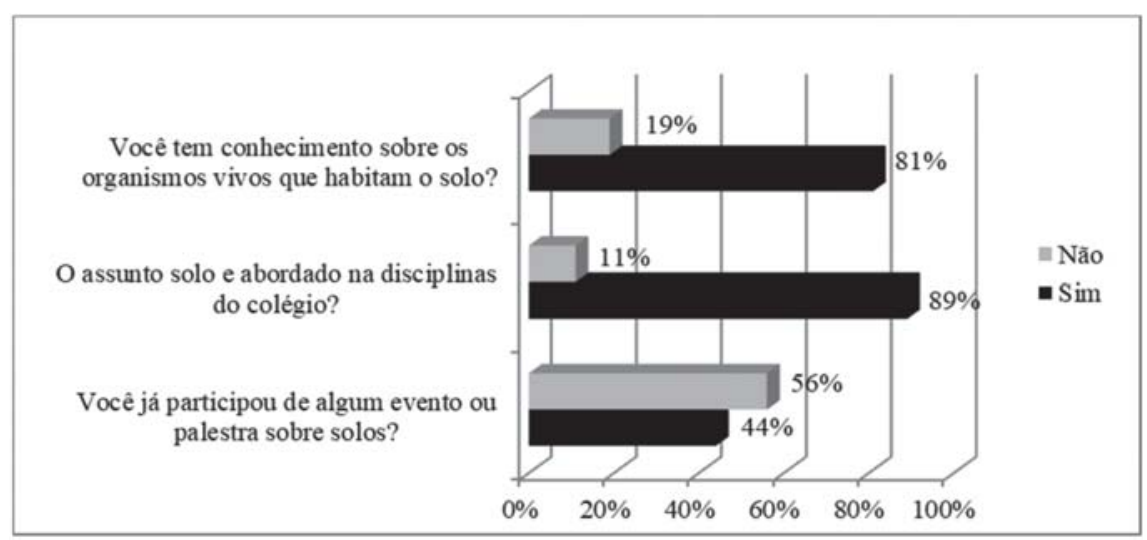

Figura 3 - Diagnóstico sobre conhecimento dos estudantes sobre os organismos do solo, estudo do solo nas escolas e participação em evento sobre solos.

geralmente reduzem a diversidade e a densidade populacional dos organismos no solo.

O assunto solo, conforme constatado é abordado nas disciplinas oferecidas aos estudantes, e este resultado se deve ao fato de município de Três Passos possuir uma política pública de incentivo a educação do campo as quais levam informações sobre as mais diversas áreas do setor agropecuário. No entanto, ressalta-se que estas atividades são desenvolvidas apenas nas escolas da rede municipal do meio rural, desta forma, quando analisada apenas a turma do meio urbano, a qual a escola não participa do projeto desenvolvido pela prefeitura municipal, observa-se que o assunto solo é muito pouco abordado nas disciplinas, sendo geralmente trabalhado de forma superficial apenas nas disciplinas de biologia e geografia, e ainda de forma superficial devido vários outros conteúdos existentes nas ementas das disciplinas. Esse resultado mostra a necessidade que este projeto do "Programa Semeando" seja desenvolvido nas demais escolas do município, não restringindo apenas algumas escolas. De acordo com Brune (2011), o Programa Semeando, implantado no final da década de 1990 no município tem por objetivo manter o jovem no meio rural e vem de encontro com a educação do campo, para promover o desenvolvimento rural e a permanência do jovem no campo, sendo que o mesmo estabelece uma forma de frear o forte êxodo dos jovens, que não veem grandes perspectivas em continuar no meio rural, indo para o meio urbano em busca de melhores condições de vida. Ainda, segundo Brune (2011), um dos objetivos 
do projeto é promover a educação ambiental, com a mudança dos hábitos sem agredir o meio ambiente, com reflorestamento, recomposição da mata ciliar, e principalmente, a recuperação e preservação do solo.

Fica evidente que a maioria dos estudantes não possui conhecimento sobre Pedologia, pois apenas $7 \%$ dos analisados atribuíram a formação do solo com o intemperismo das rochas (Figura 4). Desta forma, 93\% dos estudantes consideram que a origem do solo provinha da decomposição de plantas ou da ação do homem, sendo assim, significativo a quantidade de estudantes não possuírem o conhecimento sobre o intemperismo de rochas, e consequentemente, a formação do solo. De acordo Lima \& Lima (2007), o intemperismo é conjunto de processos físicos, químicos e biológicos que atuam sobre as rochas, desintegrando-as e decompondo-as, propiciando a formação do perfil do solo.

Segundo Peruso \& De Sena (2012), que realizaram minicurso sobre o tema solo como um recurso natural, para 12 professores da rede pública de ensino, observaram que uma das principais dificuldades dos professores é inerente ao conteúdo de pedologia: fatores e processos de formação do solo, composição geral do solo e, principais causas de degradação dos solos. Dessa forma, muitas vezes os professores encontram grandes dificuldades em trabalhar os conteúdos relacionados a Ciência do Solo em sala de aula, pois na maioria dos casos, as escolas não possuem equipamentos que permitam realização das atividades práticas as quais despertam maior interesse aos estudantes. Ainda, as escolas não possuem material didático adequado sobre tema solo, pois geralmente os livros didáticos de geografia e biologia apresentam informações resumidas ou superficiais sobre o tema solo, dificultando assim com que esse tema seja trabalhado de forma mais aprofunda. De acordo com Peruso \& De Sena (2012), são necessários materiais didáticos atualizados que contribuam para subsidiar essas discussões sobre solos.

Na Figura 5, constatou-se que 66\% dos estudantes possuem conhecimento sobre adubação verde e conservação do solo, corroborando com $64 \%$ que conhecem os benéficos da adubação verde e preservação do solo. Entretanto, observa-se que é considerável o número de estudantes que não possuem o conhecimento relacionado a estes temas, aproximadamente 1/3. Segundo Lima et al. (2016), que realizaram entrevistas com agricultores sobre a conservação do solo, 50\% dos entrevistados não possuíam conhecimento sobre este tema solo. Desta forma, torna-se necessário ações que levem tanto as estudantes quanto aos agricultores informações sobre benefícios da preservação do solo e adubação verde.

Constatou-se que percentual elevado de estudantes tem interesse em estudar o tema solos como uma disciplina na escola (Figura 5). Portanto, esta constatação fica evidente na Figura 7, onde 100\% dos estudantes consideram importante trabalhar o tema solo na escola. Desta forma, é necessário desenvolver ações de incentivo ao estudo da Ciência do Solo, uma vez que solo desempenha inúmeras funções fundamentais para vida

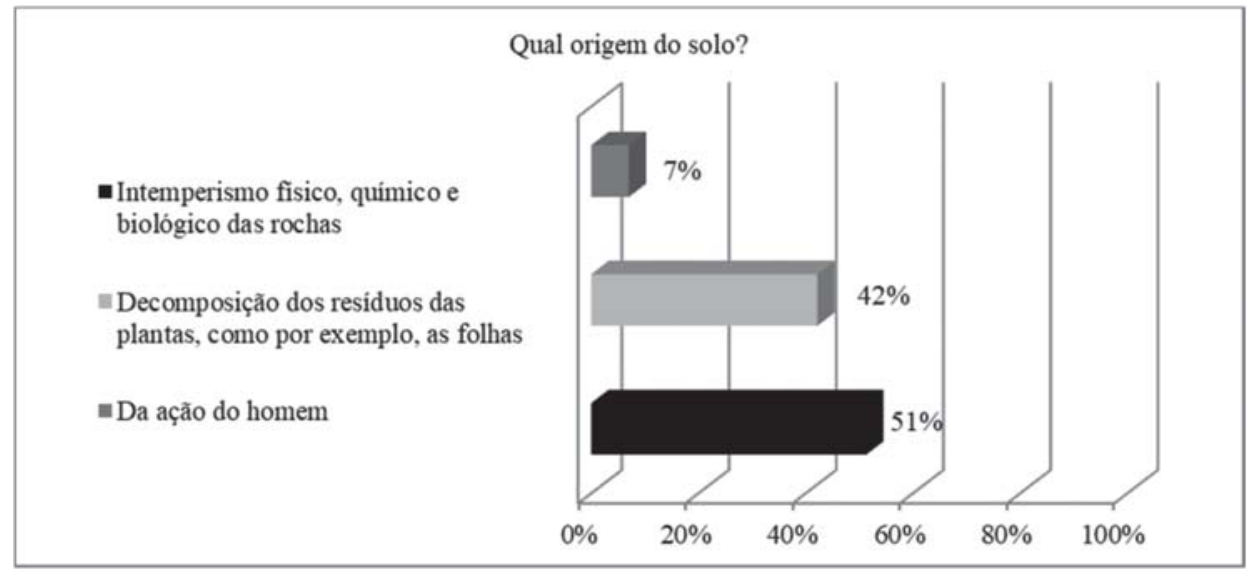

Figura 4 - Origem do solo na percepção dos estudantes. 
no planeta terra, sendo assim, o estudo dessa ciência é muito abrangente podendo ser trabalhado nas escolas nas mais variadas disciplinas oferecidas de maneira interdisciplinar, a fim de sanar a necessidade dos estudantes sobre este tema.

A maioria dos estudantes, o que representou $80 \%$ dos participantes, responderam que a principal forma de degradação do solo é erosão causada pela chuva, conforme Figura 6. De acordo com observado na Figura 5 , grande parte dos estudantes possui conhecimento sobre conservação do solo, e consequentemente, quais são causas de degradação do mesmo. Lepsch (2010), afirma que no Brasil a erosão hídrica é o tipo mais importante na degradação do solo, pois, dependendo da intensidade da chuva vários centímetros de solo poderão ser arrastados, sendo que esta camada de solo perdida levou milhares de anos para sua formação. Por esse motivo, provavelmente, grande maioria dos estudantes atribui que a principal forma de degradação do solo é aquela ocasionada pela erosão causada da chuva.

Infelizmente, a maioria da sociedade considera que um solo está erodido quando este já apresenta um estágio de degradação em nível avançado, onde dificilmente será possível reverter os danos causados a está área, ou seja, maior parte da população entende que solo está sofrendo erosão quando este já está no estágio de voçoroca. Por isso torna-se necessário

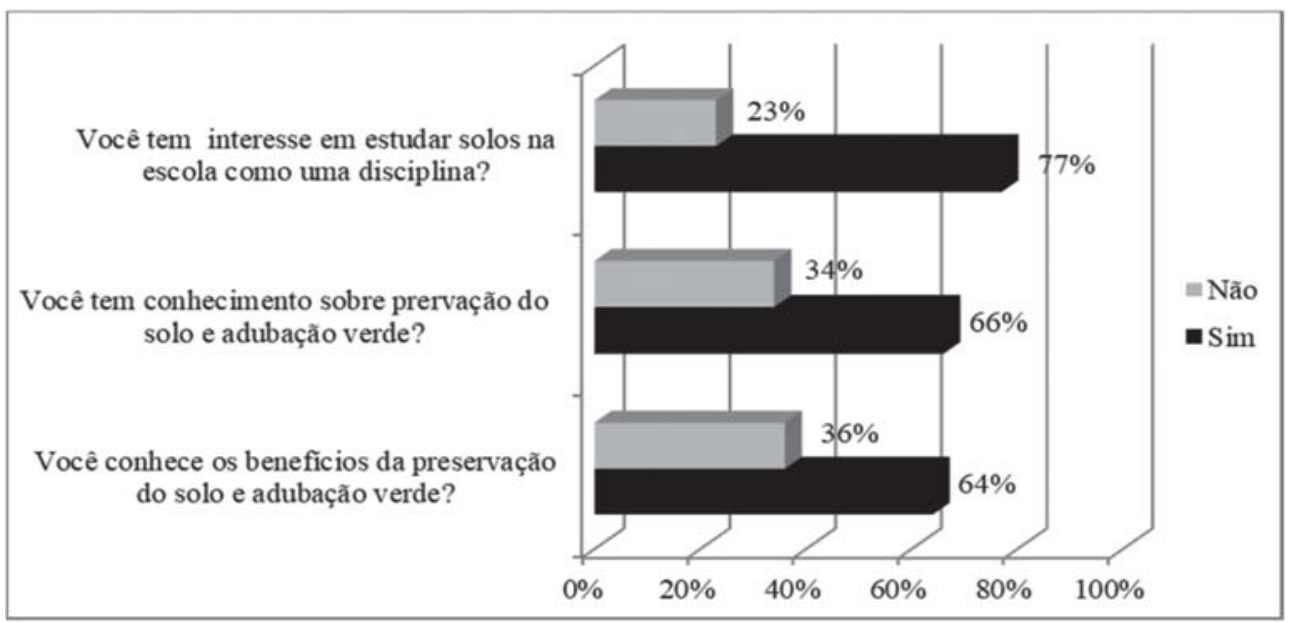

Figura 5 - Interesse dos estudantes em estudar o solo como disciplina, conhecimento que mesmos possuem sobre adubação verde e preservação do solo.

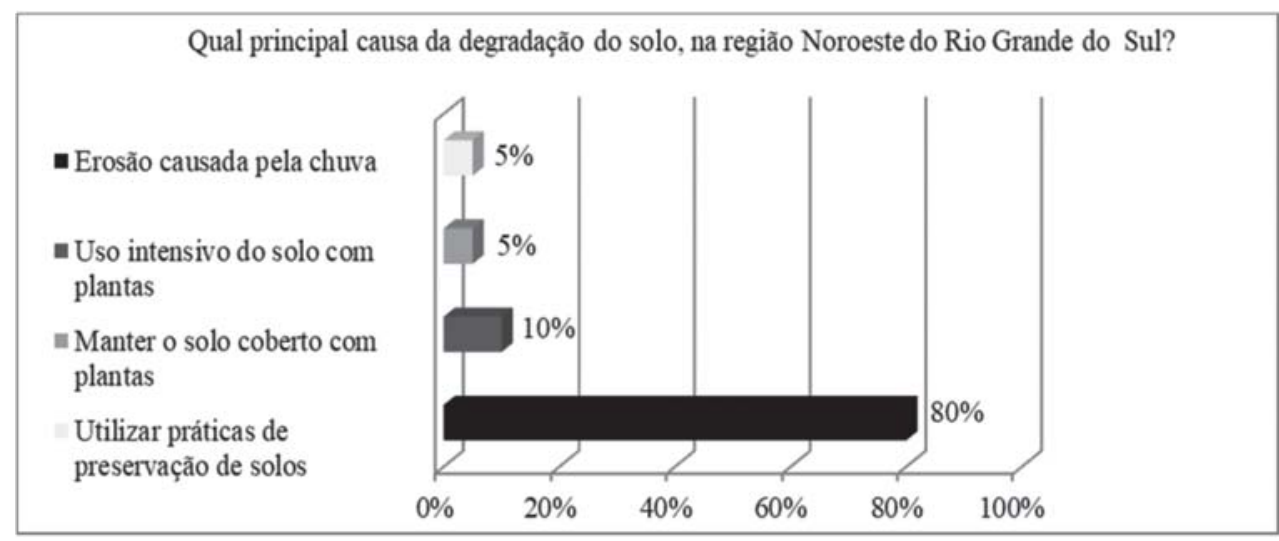

Figura 6 - Principal causa da degradação do solo de acordo com estudantes. 


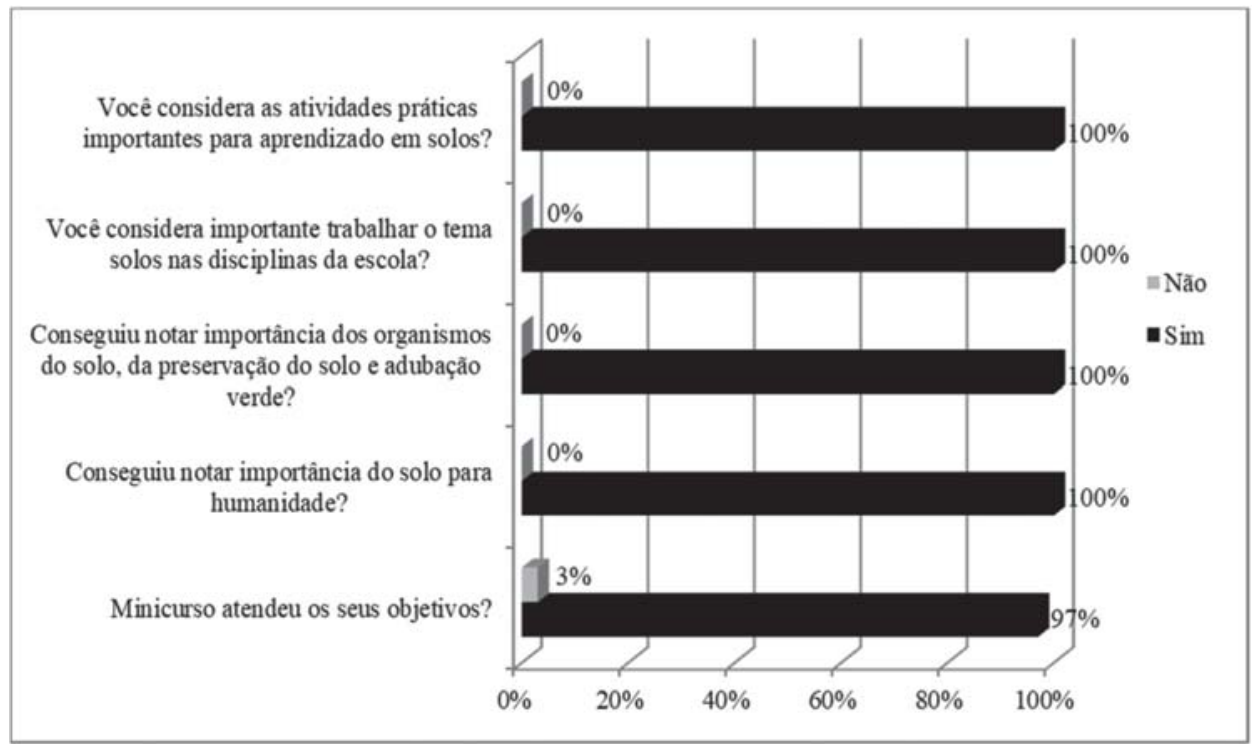

Figura 7 - Atendimento dos objetivos iniciais sobre as atividades propostas na ação de extensão dos estudantes.

a difusão de informações sobre os diferentes tipos de erosão sendo elas: erosão entre sulcos, erosão em sulco e erosão de voçoroca. De acordo Dieckow (2014), como na maioria das vezes, nos livros didáticos, somente é apresentada a erosão em voçoroca, sendo assim a população somente considera que há erosão quando vem uma enorme cratera no solo.

Existem inúmeras maneiras de evitar a erosão nas quais se destacam: cultivo em nível, uso de plantas para cobertura de solo, terraceamentos, cultivo e faixa, mínima mobilização do solo, ou seja, utilização do sistema de plantio direto. Segundo Dieckow (2014), o plantio direto é um dos meios de controle da erosão mais eficientes, e mais utilizados no Brasil. Entretanto, segundo o autor, a maioria dos livros didáticos, utilizados na educação básica, sequer faz menção a este importante método de controle, o plantio direto.

Com intuito de verificar se as atividades contribuíram para aprendizagem relacionado a Ciência do Solo, na Figura 7 , pode-se observar que $97 \%$ dos participantes afirmaram que minicurso atingiu os objetivos esperados no início do curso. Em relação à importância de trabalhar o tema solo nas disciplinas, $100 \%$ dos estudantes consideram que é importante trabalhar este tema na escola. Boas et al. (2012), em trabalho realizado em Lavras afirmam que a maioria dos professores de Biologia do ensino médio consideram importante o estudo de microrganismos do solo, ou seja, em estudar o tema solo como meio que pode suportar a vida. Desta forma, como foi observado, em que existe interesse por parte dos estudantes em estudar a Ciência do Solo, tornase necessário inclusão deste conteúdo de forma interdisciplinar nas disciplinas oferecidas pelas escolas. Também, após as atividades de extensão desenvolvidas pelo referido projeto, por unanimidade os estudantes consideram ter conseguido notar importância do solo para humanidade. Este resultado também está de acordo com encontrados por Boas et al. (2012), no qual os estudantes após atividades sobre microrganismos do solo, consideram importante o solo para humanidade, além de observarem a importância da conservação e da biologia existente no mesmo.

Os resultados na Figura 7, ainda demostram que $100 \%$ dos participantes conseguiram notar importância dos organismos do solo, preservação do solo e da adubação verde. Estes resultados colaboram com Lima et al. (2007), Lima \& Lima (2007) que afirmam que as experiências desenvolvidas por algumas universidades e escolas mostram que os alunos e professores podem ser estimulados a mudar este quadro, onde passam a incluir o solo dentro das preocupações ambientais da escola.

Ainda, todos os estudantes consideram serem importantes atividades práticas para estudo e 
entendimento do solo. De acordo com Boas et al. (2012), as ações práticas facilitam a aprendizagem sobre solos. Ainda, segundo os mesmos autores, que realizaram um trabalho semelhante no qual avaliaram a percepção dos estudantes em relação aos conteúdos sobre os microrganismos do solo, a metodologia de ensino adotada deve ser baseada nos parâmetros curriculares nacionais (PCNs), diversificada para estimular a reconstrução do conhecimento e mobilizar o raciocínio, a experimentação, a solução de problemas. Isto tudo para conseguir melhores resultados uma vez que tema solo apresenta grande complexidade quando é estudado. Tais resultados apresentados anteriormente na presente ação de extensão somente foram possíveis de serem obtidos pelo interesse dos estudantes nos temas abordados, e por isso para trabalhar a Ciência do Solo são necessárias metodologias participativas onde os estudantes sejam os próprios protagonistas do seu aprendizado.

\section{CONCLUSÕES}

As ações de extensão mostraram que os estudantes possuem conhecimento restrito sobre áreas relacionadas ao solo, como a Pedologia. Sendo assim, ainda são incipientes os conhecimentos dos estudantes sobre o solo e, aliado ao grande interesse por parte dos discentes em estudar o solo, torna-se necessário continuar no desenvolvimento de ações voltadas que promovam aprendizados sobre a Ciência do Solo. Dentre as ações, é necessário trabalhar este tema relacionado com atividades práticas, além disso, é necessário materiais didáticos atualizados ou específicos sobre Ciência do Solo nas escolas.

\section{LITERATURACITADA}

BOAS, V. et al. Microbiologia do solo no ensino médio de Lavras, MG. Revista Brasileira de Ciência do Solo, v. 36, n. 1, p. 295-306, 2012.

BRUNE, A. A contribuição do programa semeando educação e saúde na agricultura familiar para a permanência do jovem rural no distrito da floresta. 2011. 50f. TCC (Trabalho de Conclusão de Curso de Graduação Tecnológico em Planejamento e Gestão para o

Desenvolvimento Rural - PLAGEDER) - Faculdade de Ciências Econômicas da UFRGS, Porto Alegre, 2011.
DIECKOW, J. Conservação do água e solo. In: LIMA, R.M. Conhecendo os solos: abordagem para educadores do ensino fundamental na modalidade à distância. Curitiba: Departamento de Solos e Engenharia Agrícola, 2014.p.131-144.

DIONÍSIO, A. J. et al. Biologia do Solo. In: LIMA, R. M. Conhecendo os solos: abordagem para educadores do ensino fundamental na modalidade à distância. Curitiba: Departamento de Solos e Engenharia Agrícola, 2014.p.107-128.

LEPSCH, F. I. Formação e conservação dos solos. $2^{\mathrm{a}}$ ed. São Paulo: Oficina de Textos, 2010.216p.

LIMA, L. C. M. et al. Práticas de manejo e conservação do solo: Percepção de agricultores da região semiárida pernambucana. Revista Verde de Agroecologia e Desenvolvimento Sustentável, v. 11, n. 4, p. 148-153, 2016.

LIMA, C. V. et al. O solo no meio ambiente: abordagem para professores do ensino fundamental e médio e alunos do ensino médio.

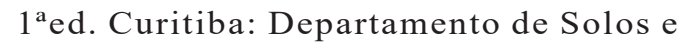
Engenharia Agrícola, 2007. 130p.

LIMA, C. V. \& LIMA, R. M. Formação do solo. In: LIMA, C. V. et al. O solo no meio ambiente: abordagem para professores do ensino fundamental e médio e alunos do ensino médio.

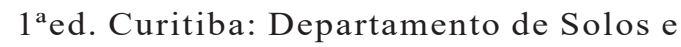
Engenharia Agrícola, 2007.p.1-10.

MAURINA, A. O êxodo rural e as transformações ocorridas na comunidade rural de Veado Pardo, município de Marau - RS. 2011. $41 \mathrm{f}$. TCC (Trabalho de Conclusão de Curso de Graduação Tecnológico em Planejamento e Gestão para o Desenvolvimento Rural PLAGEDER) da Faculdade de Ciências Econômicas da UFRGS, Camargo, 2011. 
MUGGLER, C. C. et al. Educação em solos:

Princípios, teoria e métodos. Revista

Brasileira de Ciência do Solo, v. 30, n. 4, p. 733-740, 2006.

PERUSI, M. C. \& DE SENA, C. C. R. G. Educação em solos, educação ambiental inclusiva e formação continuada de professores: múltiplos aspectos do saber geográfico. Entre Lugar, v. 3 , n. 6, p. 153-164, 2012.

Recebido para publicação em 24/7/2018 e aprovado em 7/9/2018.
REDIN, M. et al. Plantas de cobertura de solo e agricultura sustentável: espécies, matéria seca e ciclagem de carbono e nitrogênio. In: TIECHER, T. (Org.). Manejo e conservação do solo e da água em pequenas propriedades rurais no sul do Brasil: práticas alternativas de manejo visando a conservação do solo e da água. Porto Alegre: UFRGS, 2016, p. 7-22.

WHITE, R. Princípios e práticas da ciência do solo: solo como recurso natural. $4^{\mathrm{a}}$ ed. São Paulo: Andrei, 2010. 426p. 